\title{
Soluble and Stable Zethrenebis(carboximide) and Its Quinone
}<smiles>O=C1C(=O)c2ccc(Br)c3c(Br)ccc1c23</smiles>

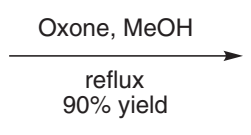<smiles>O=C1OC(=O)c2ccc(Br)c3c(Br)ccc1c23</smiles>

\section{$\stackrel{\text { 2,6-diisopropylaniline }}{\longrightarrow}$ acetic acid, reflux $29 \%$ yield}<smiles>CC(C)c1cccc(C(C)C)c1N1C(=O)c2ccc(Br)c3c(Br)ccc(c23)C1=O</smiles>

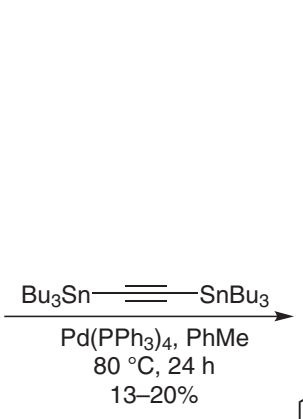<smiles>CC(C)c1cccc(C(C)C)c1N(C=O)C=O</smiles>

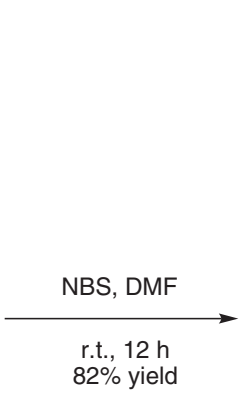<smiles>CC(C)c1cccc(C(C)C)c1C(=O)n1c(=O)c2ccc3c(=O)c4c5c6ccc7c(=O)n(-c8c(C(C)C)cccc8C(C)C)c(=O)c8ccc(c-5c1c1ccc4c3c21)c6c78</smiles>

2

\section{Key words}

\section{zethrene}

polycyclic aromatic hydrocarbons

\section{quinones}

Significance: Despite first being synthesized decades ago by Clar and co-workers, zethrene only recently began attracting major interest due to its potentially interesting optoelectronic properties. Poor air and light sensitivity of unsubstituted zethrene would not have aided its cause. A more convenient route to zethrene was found in the 1960's during attempts to synthesize and isolate the unstable tetradehydrodinaphtho[10]annulene, a precursor of zethrene. This was not successfully done until last year.

SYNFACTS Contributors: Timothy M. Swager, Joel Batson Synfacts 2010, 12, 1357-1357 Published online: 22.11.2010 Dol: 10.1055/s-0030-1258940; Reg-No.: S14210SF
Comment: Employing the same strategy discovered by Staab and Sondheimer in the 1960's, the authors take advantage of the automatic transannular cyclization of the tetradehydrodinaphtho[10]annulene to form the butadiene core of the zethrene. Meanwhile, the overall improved stability of 1 no doubt makes it an interesting compound for further optoelectronic studies. Extremely notable as well is that attempts to brominate $\mathbf{1}$ using $\mathrm{N}$-bromosuccinimide in the presence of DMF unexpectedly leads to the formation of the respective quinone $\mathbf{2}$. 